\title{
Skull morphology and its neurosurgical implications in the Hippocratic era
}

\author{
Vassilios G. Dimopoulos, M.D., ${ }^{1}$ IOANnis Z. KaPSALAKIS, M.D., ${ }^{2}$ AND \\ Kostas N. Fountas, M.D., PH.D. ${ }^{3}$ \\ ${ }^{1}$ Department of Neurosurgery, Strong Memorial Hospital, University of Rochester, \\ Rochester, New York; ${ }^{2}$ Department of Neurology, General Hospital of Athens, Athens, Greece; \\ ${ }^{3}$ Department of Neurosurgery, University Hospital of Larisa, School of Medicine, \\ University of Thessaly, Larisa, Greece
}

\begin{abstract}
$\checkmark$ Differences in skull morphological characteristics among various human populations were first described by Herodotus of Halicarnassus. The Hippocratic treatise On Head Wounds ( $\Pi \varepsilon \rho \imath \tau \omega v \varepsilon v$ $\kappa \varepsilon \phi \alpha \lambda \eta \tau \rho \omega \mu \alpha \tau \omega \nu)$ provided the first detailed description of human skull anatomy. The Hippocratic author presented the first systematic attempt to create a classification system of skull and cranial suture morphology. Detailed descriptions of various human skull types and cranial sutures were provided along with information regarding the macroscopic structure and thickness of different parts of the skull. The significance of skull thickness in patients with head injuries was also presented in the Hippocratic text. The authors discuss the influence of this treatise on the later development of descriptive skull anatomy and on the development of modern neurosurgery. (DOI: 10.3171/FOC-07/07/E10)
\end{abstract}

Key Words • craniology • head injury • Hippocrates • history of medicine • skull - sutures

\section{First Descriptions of Skull Morphology}

Variation in the morphology of the human skull was first reported by Herodotus of Halicarnassus (484-425 $\mathrm{BC})$, who described differences in the thickness of the skull between the Egyptians and the Persians. ${ }^{8}$ In his work Historiae, he described his observations and findings after examining a collection of skulls from Egypt and Persia. Herodotus performed a primitive scientific experiment by tossing stones at the studied skulls and observing which ones broke easier. He noticed that Egyptian skulls resisted breaking and concluded that Egyptians had thicker skulls than Persions. He explained his findings by the fact that Persians traditionally wore caps while Egyptians did not. Thus, he postulated that Egyptians gradually developed thicker skulls as a physical compensatory mechanism. ${ }^{8}$ Herodotus believed that environmental causes were responsible for the observed variability in skull thickness.

Similarly, in the Hippocratic treatise On Head Wounds, ${ }^{8}$ the author (Hippocrates or one of his students) described in detail the significant variation in skull and cranial suture morphology. Later, Galen of Pergamon (130-200 $\mathrm{AD})$ and then Andreas Vesalius (1514-1564 AD) recognized the differences in the morphology of the human skull and cranial sutures, and associated certain skull characteristics with clinicopathological entities today identified as hydrocephalus or craniosynostosis.

In the present paper, we present the original description of different skull morphological types provided in the work On Head Wounds and discuss the influence this first attempt at human skull classification has had on our understanding of the surgical anatomy of the central nervous system, and subsequently, on the development of modern neurosurgery.

\section{On Head Wounds}

On Head Wounds ( $\Pi \varepsilon \rho \imath \tau \omega v \varepsilon v \kappa \varepsilon \phi \alpha \lambda \eta \tau \rho \omega \mu \alpha \tau \omega v)$ consists of 21 chapters, with the craniology information presented in the first two chapters. The ancient Greek text and two modern English translations of it ${ }^{7,8}$ were studied and thoroughly reviewed for any information concerning human skull and cranial suture morphology, and its significance in the management and outcome of head injury. Characteristic passages from the most recent modern English translation by Maury Hanson ${ }^{8}$ are quoted.

\section{Skull Shape Variability}

The first two chapters of the treatise were dedicated to a detailed description of the shape of the human skull, its variations, and the morphology of the cranial sutures. In the beginning of the first chapter, the Hippocratic author made a clear statement that: "the heads of men are not all alike, nor are the cranial sutures arranged the same in all." ${ }^{8}$ This statement emphasizes the fundamental principle of modern physical anthropology-variability.

Four discrete skull types were described in the text. The 
first was characterized by a prominence at the front of the head. In this type, the cranial sutures were arranged in a Tshaped configuration. The author wrote: "He who has a prominence at the front of his head-a prominence is a rounded projection of the bone beyond the other (bone)-has his cranial sutures arranged as the letter tau (T) is written."

The second type was described as characterized by an osseous prominence at the back of the skull: "but he who has the prominence at the back of his head has his sutures arranged the reverse of the former."

The third type was characterized by the presence of osseous prominences at the front and the back of the head. The sutures formed an $\mathrm{H}$ shape. "And he who has a prominence at both ends of his head, both front and back, in the same manner has his sutures arranged as the letter eta $(\mathrm{H})$ is written."

In the fourth skull type there were no osseous prominences, and the cranial sutures were arranged in an Xshaped configuration: "But he who has no prominence at either end has his cranial sutures as the letter chi (X) is written."

\section{Skull Thickness}

The Hippocratic author also discussed the macroscopic structure and texture of skull bones. Skull bones were described as double bones with a hard outer layer and softer inner layer lying next to the membranous structure now identified as the dura mater.

The bone of the midpart of the skull is double. The hardest and densest part of it is both the outermost, the even surface of the bone just under the scalp, and the innermost, the even undersurface of the bone, next to the membrane (dura mater); passing from the outermost and innermost layers the bone always goes from the hardest and densest parts to the softer, less dense and more porous bone and into the diploe. And the diploe is the most porous and the softest part, especially full of empty spaces.

In the second chapter, the author commented on skull thickness, clearly stating that different anatomical parts of the skull demonstrated various degrees of skull thickness. He noted that the bregmatic area was the most thin and weak part of the skull, and that therefore the underlying brain was more vulnerable to injuries in this region than in any other.

But, in respect to thickness and thinness, the bone at the bregma is the thinnest and weakest of the entire skull, and in this part of the skull the bone has the least and thinnest flesh over it, and there is the most brain under this part of the skull. The result of such an arrangement is that, when someone is wounded equally or less-the wounds and weapons being the same size or smaller-the bone in this part of the skull is more readily crushed, fractured or crushed in, and (the injuries) are more often fatal, and medical cure and escape from death more difficult (with wounds) here than in any other part of the head.

The temporal area was identified as the second thinnest part of the skull: "Of the other parts, that at the temples is weakest." Surgical intervention for the treatment of temporal injuries was strongly discouraged by the Hippocratic author.

The now well-known intrinsic epileptogenecity of the temporal lobes and the development of seizures contralateral to the injured temporal lobe were clearly described in Chapter 13.

But this part, the temple and the area above it in the region of the blood vessel which traverses the temple, should not be incised. For spasm then seizes the patient. And if the incision is made in the left temple, spasm seizes the right side (of the body), and if the incision is made in the right temple, spasm seizes the left side (of the body).

\section{Factors Affecting Survival Time After Head Injury}

The Hippocratic writer observed that patients with fatal head injuries at the posterior part of their heads had a longer survival time relative to patients who had suffered injuries of the same mechanism and severity to the anterior part of their heads. He explained this observation by the increased skull thickness of the posterior part of the head, which functioned as a mechanical barrier for the propagation of suppuration to the underlying brain. In addition, the author believed that less brain volume was present at the back of the head: "And if a person is going to die in any case from the wound, he who has his wound at the back of the head will take a longer time to die. For suppuration of the bone takes a longer time to occur and to penetrate down to the brain because of the thickness of the bone. Also less brain lies under this part of the skull."

The author concluded the second chapter with the observation that patients with fatal head injuries survived longer in winter, when temperatures were lower: "Also, whoever is going in any case to die from his wound, wherever on the head he may have the wound, lives longer in winter than in summer."

\section{Discussion}

The treatise On Head Wounds was one of the surgical books of the Hippocratic Medical Library and is considered by many historians to be an original work of Hippocrates (460-377 BC) himself. ${ }^{5}$ However, a few historians have questioned the authorship of this book, arguing that it was written by one or a group of Hippocrates' students. ${ }^{2.5}$ In the present paper, the term "Hippocratic author" was used in lieu of Hippocrates because the authorship issue has remained controversial. It is also uncertain if the ancient text that we have today represents the entire original work or if a part has been lost. ${ }^{5}$ Galen wrote that there was an addendum to the treatise, which was lost. ${ }^{6}$ The issue of the completeness of this Hippocratic treatise remains unresolved.

Independent of authorship and completeness issues, $\mathrm{On}$ Head Wounds was the first scientific text attempting to present the management of head injuries in a thorough and systematic way. The text was written not only for physicians of the time, but also as a book of guidelines for the management of head injury for the succeeding generations of physicians. ${ }^{1}$ The importance of meticulous knowledge of human anatomy, especially skull anatomy, in understanding head injuries was emphasized in the text by dedicating the first two chapters of the book to descriptions of skull anatomy and variations in normal anatomy. The author presented a classification system of skull morphol- 
ogy by describing four different skull morphological patterns in the first chapter. This classification scheme was apparently based on systematic observation and autopsy material. The scientific significance of this Hippocratic work becomes even greater when we consider the historical and cultural conditions of the era. It must be mentioned that the number of craniotomies and autopsies performed was very limited at the time this book was written (5th and 4th century BC), and the available surgical instruments were very primitive. ${ }^{1,2,9}$ In addition, there were no specialist surgeons but rather a very few physicians who specialized in the treatment of bone fractures and subluxations and had some familiarity with the use of the primitive and rare surgical instruments. ${ }^{5}$ In On Head Wounds, ${ }^{8}$ the Hippocratic author provided not only accurate anatomical descriptions of the skull, but also introduced the idea of anatomical variation, a concept of paramount importance in differentiating the normal from the abnormal.

The clinical significance of skull anatomy in the severity and overall outcome of patients sustaining head injuries was addressed in the second chapter of the Hippocratic treatise. The skull thickness was clearly identified as a factor affecting outcome. The author stated that patients sustaining bregmatic or temporal area injuries had worse outcomes than patients with head injuries of the same severity to different areas of the head. The unique anatomical features of the temporal lobe were identified and their clinical significance further emphasized by the author in Chapter 13; surgical intervention in the temporal area was strongly discouraged for fear of causing postoperative seizures. The epileptogenicity of the anatomical structures of the temporal lobe was apparently known to the author, as well as the fact that neurological signs occur controlaterally to the site of the lesion.

The author believed that patients who sustained fatal injuries to the back of the head would survive longer because of the increased skull thickness of this area. It is well known in modern neurosurgery that posterior fossa anatomical structures are very sensitive and head injuries at this area generally have worse outcome. It needs to be considered, however, that the mechanisms of head injuries were different at the Hippocratic era. The majority of the head injuries were the result of sharp, light weapons and low-velocity impacts. In contrast to the present era, highvelocity impacts were extremely rare. It is possible that posttraumatic infection was the most common fatal mechanism in patients with these head injuries, and that therefore increased skull thickness would delay infections by acting as a mechanical barrier, thus prolonging the survival time of patients with injuries to the back of the head. The Hippocratic writer also observed that patients who suffered fatal head injuries survived longer during winter. This observation may signal the author's recognition of the role of increased temperature in the infectious process, and furthermore may be considered the scientific basis of the modern hypothermia protocols applied in patients with severe head injuries.

The Hippocratic text, and particularly the craniology data it provides, was a source of inspiration for subsequent giants of anatomy such as Galen of Pergamon and Andreas Vesalius. Characteristically, in Chapter V of the first book of Fabrica, Vesalius presented one natural (normal) and four unnatural (abnormal) types of human skull., ${ }^{3,40-12}$ The normal and the first three abnormal types were very similar to the skull types provided in the Hippocratic text. ${ }^{3,4,10-12}$ In addition, the description and terminology Vesalius used to describe the cranial suture morphology in Chapter VI were the same as those in the Hippocratic text. ${ }^{3,4,10-12}$ Interestingly, some of the modern principles in the description of craniosynostosis and the currently used nomenclature can be identified in Vesalius' monumental text.

\section{Conclusions}

The Hippocratic treatise On Head Wounds included the first serious, scientific attempt at descriptive skull anatomy. This work was based on meticulous and systematic observation and remained free of any religious preoccupation or purpose. The recognition of anatomical variations and the need to establish a classification scheme were novel scientific concepts introduced by the Hippocratic author. Finally, the significance of meticulous anatomical knowledge in the treatment of patients with head injuries first identified in this text has greatly influenced the development of modern neurosurgery.

\section{References}

1. Dimopoulos VG, Fountas KN, Machinis T, Robinson JS: Head injury management algorithm as described in Hippocrates' "peri ton encephali traumaton." Neurosurgery 57:1303-1305, 2005

2. Dimopoulos VG, Robinson JS III, Fountas KN: Pearls and pitfalls of skull trephination in the Hippocratic text "Peri Ton Encephali Traumaton" J Hist Neurosci (in press)

3. Goodrich JT: Sixteenth-century Renaissance art and anatomy: Andreas Vesalius and his great book-a new view. Med Herit 1:280-288, 1985

4. Hast MH, Garrison DH: Vesalius on the variability of the human skull: Book I Chapter V of De Humani Corporis Fabrica. Clin Anat 13:311-320, 2000

5. Hatzopoulos O: Hippocrates Apanta, Vol. 8. Athens: Kaktos Editions, 1993, pp 17-65

6. Herodotus of Halicarnassus: The Histories: Book II. New York: Penguin, 1972

7. Hippocrates: The Genuine Work of Hippocrates. Adams F, translator. London: The Sydenham Society, 1886

8. Hippocrates: Hippocrates: On Head Wounds. Hanson M, ed. and trans. (Corpus Medicorum Graecorum I 4.1.) Berlin: Akademie Verlag, 1999

9. Martin G: Was Hippocrates a beginner at trepanning and where did he learn? J Clin Neurosci 7:500-502, 2000

10. O'Rahilly R: Commemorating the Fabrica of Vesalius. Acta Anat (Basel) 148:228-330, 1993

11. Vesalius A: Andreas Vesalius: On the Fabric of the Human Body. Richardson WF, Carman JB, trans. San Francisco: Norman Publishing, 1998, pp 45-64

11. Tan SY, Yeow ME: Andreas Vesalius (1514-1564): father of modern anatomy. Singapore Med J 44:229-230, 2003

Manuscript submitted April 23, 2007.

Accepted in final form June 24, 2007.

Address reprint requests to: Kostas N. Fountas, M.D., Ph.D., Department of Neurosurgery, University Hospital of Larisa, Lambrou Katsoni Street, Terpsithea 41500, Greece. email: knfountas md@excite.com. 